\title{
Characterization of magnetic minerals within alkali and tholeiitic basalts in Penghu islands of Taiwan
}

\author{
CHUN-HAO LO ${ }^{1}$, YeN-HUA CHEN ${ }^{1 *}$, AND CHORNG- \\ SHERN HORNG ${ }^{2}$ \\ ${ }^{1}$ Department of Earth Sciences, National Cheng Kung \\ University, Tainan, Taiwan. ji351212@gmail.com \\ ${ }^{2}$ Department of Earth Sciences, National Cheng Kung \\ University, Tainan, Taiwan. yhc513@mail.ncku.edu.tw \\ ${ }^{3}$ Institute of Earth Sciences, Academia Sinica, Taipei, \\ Taiwan. cshorng@earth.sinica.edu.tw
}

The mineral characterization can dominate the rock property. Therefore, to fully understand mineral magnetism is very imperative to study rock magnetic properties. Here we study rock magnetic properties of two types of basaltic rocks (alkali and tholeiitic basalts) adopted from Penghu islands in Taiwan. The alkali basalt in Dinggou Islet has relatively high magnetic susceptibility but rather unstable remanent magnetization, however, the tholeiitic basalt in Daguoye Islet shows low magnetic susceptibility but stable remanent magnetization. In order to understand the reason that cause the difference in rock magnetic characteristics, we study the mineral properties (including magnetic mineral identification, chemical state, magnetic domain structure, etc.) within these two types of rocks.

Our results indicate that there are two kinds of magnetic minerals in tholeiitic basalt and it has a higher degree of oxidation based on the results of the XRD and X-ray photoelectron spectroscopy (XPS). A higher ratio of singledomain magnetic structure produces a stable natural remanent magnetism (NRM), while the results of magnetic force microscopy (MFM) also correspond with the results of thermal demagnetization. Conversely, there is only one kind of magnetic mineral in the alkali basalt, but the higher ratio of multi-domain structure leads to an unstable NRM. The lamellar-magnetism structure in tholeiitic basalt is also observed. To sum up, the phase difference of magnetic minerals leads to different rock magnetic properties. Moreover, the tholeiitic basalt in Penghu islands is a better sample candidate for studying paleomagnetism, while MFM analyses can be used to determine magnetic direction and applied in the geomagnetic field. 